* Possui graduação em Direito pela Universidade Federal de Santa Maria (1976), mestrado em Direito pela Universidade Federal de Santa Catarina (1990) e doutorado em Direito pela Universidade Federal de Santa Catarina (1997). Atualmente é professor do doutorado da Universidade de Granada e professor associado da Universidade Federal de Santa Catarina. É membro do IDASC - Instituto de Direito Administrativo de Santa Catarina. É pesquisador 2 em produtividade do $\mathrm{CNPq}$. E-mail:scademartori@uol. com.br.

** Possui graduação em Direito pela Universidade do Vale do Rio dos Sinos (1996), Especialização em Integração e Mercosul pela UFRGS (1999), Mestrado em Relações Internacionais pela Universidade Federal do Rio

\section{GLOBALIZAÇÃO, CONSTITUIÇÃO \\ E POLÍTICA EXTERNA: ANALISE \\ COMPARADA DA PARTICIPAÇÃO \\ CIDADÃ NO BRASIL, CHILE E \\ COLOMBIA}

\section{GLOBALIZATION, CONSTITUTION}

AND FOREIGN POLICY: COMPARATIVE

ANALYSIS OF CITIZEN PARTICIPATION

IN BRASIL, CHILE AND COLOMBIA.

\begin{abstract}
Sérgio Urquhart de Cademartori* José Alberto Antunes de Miranda**
\end{abstract}

Como citar: CADEMARTORI, Sérgio Urqukart de. MIRANDA, José Alberto Antunes de. Globalização, constituição e política externa: analise comparada da participação cidadã no Brasil, Chile e Colombia. Revista do Direito Público, Londrina, v. 11, n. 3, p.311-345, dez. 2016. DOI: 10.5433/1980-511X.2016v11n3p311. ISSN: 1980-511X.

Resumo: O Estado soberano é, em regra, a pessoa estabelecida de direito público com capacidade de representação e interlocução no âmbito internacional. Há indícios consistentes de que institucionalidades liberais e democráticas dão primazia ao poder Executivo na formação 
da agenda da política externa, em países presidencialistas ou parlamentaristas. $\mathrm{O}$ objetivo desse trabalho é realizar um estudo comparativo dos mecanismos existentes nas Constituições do Brasil, da Colômbia e do Chile de participação da sociedade civil no âmbito da política externa. O método de trabalho constitui-se no exame do referencial teórico sobre o tema e análise das Constituições existentes nos respectivos países que demostrem ou não haver mecanismos de participação da sociedade civil mais efetivos na política externa. São percebidas a partir da análise das constituições do Brasil, do Chile e da Colômbia mudanças muito lentas no sentido de maior participação da sociedade civil na produção da política externa no âmbito desses países. A participação da sociedade civil é estritamente pontual, muito em função do que determina a Constituição dos mesmos.

Palavras Chaves: Democracia. Constituição. Política Externa.

Abstract: The sovereign state is, as a rule, the entity established under public law with representation and capacity for dialogue in an international level. There is consistent evidence that liberal and democratic institutions give primacy to the executive power when shaping foreign policy in presidential and parliamentary countries. This paper aims to conduct a comparative study of the constitutions of Brazil, Colombia, and Chile on the existing
Grande do Sul (2004) e Doutorado em Estudos Estratégicos Internacionais pela UFRGS (2012). Atualmente é Assessor de Assuntos Interinstitucionais e Internacionais e professor permanente do Mestrado em Direito e Sociedade além de integrar o corpo docente do Curso de Relações Internacionais do Centro Universitário La Salle. E-mail: jose.miranda@ unilasalle.edu.br. 
mechanisms that allow for civil society's participation in foreign policy. The preferred method of study is the examination of the theoretical framework of participation and analyzes the constitutions that show possible mechanisms of civil society's participation in foreign policy. However, the result of this study indicates that the constitutions of Brazil, Chile, and Colombia indicates a slow change towards greater participation of civil society in the production and influencing of foreign policy within these countries. In conclusion, the current participation of civil society is strictly punctual and varies depending on the structural shape of the constitution of these countries.

Keywords: Democracy. Constitution. Foreign Policy. 


\section{INTRODUÇÃO}

O processo de globalização promoveu maior aproximação entre os Estados a partir da imposição de uma nova ordem onde o Estado, até então considerado soberano, passa a não ser mais capaz de controlar algumas de suas principais atividades. A sociedade nos tempos atuais vive mais a insegurança da regulação tradicional que hoje se apresenta mais fragilizada. A globalização eleva os Estados em direção a uma sociedade mundial. Os movimentos da sociedade civil aparecem não como simples movimentos reivindicatórios, mas como expressão de uma verdadeira vontade de participação por parte dos cidadãos.

São os efeitos paradoxais de exclusão e fragmentação da globalização que oferecem grande escopo por colaboração e cooperação entre o Estado e a sociedade civil. Isso é uma forma no qual o governo pode garantir que tem suficiente informação para construir decisões informadas sobre o gerenciamento de uma variedade de imperativos e desafios que vem a partir da globalização.

O Estado soberano é, em regra, a pessoa estabelecida de direito público com capacidade de representação e interlocução no âmbito internacional. Apenas o Estado soberano pode fazer a política externa stricto sensu. Esse dado indica a tendência de grande concentração dos poderes de decisão sobre assuntos internacionais nas mãos de poucos. A forma como o Estado se organiza institucionalmente e dispõe internamente os seus poderes político-administrativos impactará a produção de sua política externa.

Michael Doyle advoga por uma comunidade de Estados autenticamente liberais dada a característica inerente a regimes democráticos de respeitar e dialogar com outros países democráticos 
antes de recorrer ao conflito. Segundo Doyle (1999) a substituição dos mecanismos de balanço de poder e da guerra por instituições conducentes à maior cooperação entre os Estados, como o direito internacional e as organizações internacionais, levam à promoção dos valores democráticos. ${ }^{1}$

No âmbito dessa proposta, uma ordem internacional requereria uma espécie de cruzada, isto é, a mobilização dos verdadeiros Estados democráticos para preservar e expandir a sociedade internacional. $\mathrm{O}$ formato liberal do Estado assenta na premissa da repartição de poderes. $\mathrm{O}$ princípio federalista dos freios e contrapesos aplica-se à maioria absoluta das comunidades políticas democraticamente organizadas do mundo contemporâneo.

Salvo algumas exceções, as institucionalidades liberais e democráticas distribuem competências entre os ramos Executivo, Legislativo e Judiciário, idealmente independentes entre si. Como já demonstrado em inúmeros estudos, as relações estabelecidas entre esses ramos também podem impactar a forma de produção da politica externa do Estado. (DOYLE, 1999).

O objetivo desse trabalho é realizar um estudo comparativo dos mecanismos existentes nas Constituições do Brasil, da Colômbia e do Chile de participação da sociedade civil no âmbito da política externa. O método de trabalho constitui-se no exame do referencial teórico sobre o tema e análise das Constituições existentes nos respectivos países que demonstrem ou não haver mecanismos de participação da sociedade civil mais efetivos na política externa.

Há indícios consistentes de que institucionalidades liberais e

1 Nesse trabalho se entende por balanço de poder ou equilíbrio de poder o quinto sentido da expressão trazido por Martin Wight, quando é empregado para descrever uma tendência inerente da política internacional no sentido de produzir uma distribuição equitativa de poder. Isto é uma afirmação geral a respeito de como os agrupamentos de potencias encontram-se em um equilíbrio que muda constantemente. (WIGHT, 2002). 
democráticas dão primazia ao poder Executivo na formação da agenda da política externa, em países presidencialistas ou parlamentaristas. Ao legislativo é geralmente reservado o poder da ratificação/veto e de emenda. Ou seja: existiria, por forca da própria composição do Estado institucional contemporâneo uma propensão inercial a concentração de recursos (no Executivo) quando de trata de tomada de decisão em temos de política exterior. ${ }^{2}$

Alguns autores ainda indicam um outro aspecto que compromete a democratização da esfera da política exterior do Estado - a baixa capacidade técnica das legislaturas. A carência de capacidade técnica no legislativo para avaliar políticas públicas, de maneira geral, implica negligencia da agenda internacional do Estado. Tal característica confere ao executivo em muitos países grande influência na formulação de programas e leis aumentando a atratividade do gabinete não apenas para atores políticos com objetivos clientelísticos, mas também para aqueles com motivações programáticas.

Em parlamentos bicamerais há indicações de que a câmara baixa é mais sensível às manifestações da opinião pública, em matéria de política externa, do que os senadores e os funcionários oficiais do poder Executivo devido, principalmente ao insulamento destes, proporcionados por seus mandatos mais longos e não necessariamente constrangidos pela pressão popular. (AMORIN NETO, 2006; JACOBS; PAGE, 2005).

\section{O CONTROLE DE POLÍTICA EXTERNA}

O controle da política externa dos Estados por parte do cidadão é

2 Quanto mais complexa e ou saliente é a questão em apreciação, mais pronunciada será a capacidade de o Poder Executivo estabelecer a agenda internacional do Estado. (MILNER, 1997). 
algo historicamente sensível no âmbito das discussões sobre democracia, constituição e política. Em muitos países o controle de relações externas está fixado por meio de princípios instituídos nas Cartas Magnas dos Estados. Esses princípios orientam as relações exteriores dos Estados que são fiscalizados pelos parlamentos. A participação do cidadão se dá por meio indireto via Parlamento, não sendo comum o envolvimento mais direto no acompanhamento desses temas.

Esse crescente incremento do grau de complexidade do quadro das relações internacionais, com a multiplicação do número de protagonistas e procedimentos, faz aflorar a questão crucial da pluralidade de ordenamentos jurídicos, isto é, da impraticabilidade efetiva que se constata de se subordinar a um único sistema de normas toda a imensa gama de fatos jurídicos que se manifestam no plano internacional. (DALLARI, 1994).

No âmbito da normatização das relações internacionais, o pluralismo jurídico se manifesta na medida em que o direito internacional construído a partir da vontade dos Estados soberanos - e como projeção dos respectivos ordenamentos - convive com outros sistemas de regras, edificados com base na vontade de outros protagonistas que não os Estados.

Como bem aponta Wolkmer (2015, p. 150-151) a crise da representação política e da superação do paradigma monista liberal individualista na esfera do Estado e do Direito se agrava ainda mais em contextos fragmentários, tensos e explosivos como os dos países latinoamericanos, marcados por acentuada tradição autoritária- clientelista.

Na medida em que, aparentemente, se verifica um movimento no sentido da acentuação do pluralismo de ordenamentos jurídicos na esfera internacional, com a consequente perda de peso relativo do sistema 
de normas fundado na vontade dos Estados soberanos, poder-se-ia questionar a causa da preocupação atual com o tratamento de relações exteriores de um país no âmbito do ordenamento jurídico estatal, no sentido de permitir maior participação da sociedade civil no âmbito das decisões de política externa.

A principal resposta que se dá é que não necessariamente se pode caracterizar como inevitável - e mesmo conveniente - a diluição do potencial normatizador do ordenamento estatal no tocante às relações internacionais. A representação política vai se revelando pouco habilitada para o exercício das funções de integração social, de produção de identidades coletivas e de socialização política. Há um distanciamento das estruturas de representação parlamentar, limitadas para enfrentar situações cada vez mais complexas, crescendo assim a presença de corpos intermediários e de movimentos participativos orientados por uma racionalidade diversa do formal. (CAMPILONGO, 1987).

A institucionalização, enquanto ritualização normativa que internaliza critérios de legitimidade, busca, na sociedade moderna, consagrar certos padrões oficiais de implementação de decisões coletivas, como negociações, compromissos, representação, regras da maioria, organismos burocráticos, regulação-integração social. É a institucionalização desvirtuada - tanto a rotina estabilizante e o formalismo não criador quanto o regime artificial de acomodamento das relações sociais e das formas de organização - que se pode contrapor à contingencia e autenticidade dos movimentos sociais, que passam a estabelecer novas exigências, orientações e experiências concretas que contextualizam a pluralidade de um espaço de política não institucional. (WOLKMER, 2015).

É então inexorável observar-se que o conjunto de regras do 
ordenamento jurídico estatal, ao expressar e, simultaneamente, influenciar preocupações, ideias e valores presentes na sociedade, interfere nos demais ordenamentos jurídicos lastreados nessa mesma sociedade e com eles interage.

$\mathrm{Na}$ literatura sobre política externa vários argumentos são trazidos no sentido de distanciar o contato do cidadão das decisões sobre a matéria. Dentre os argumentos trazidos em favor dessa tese ressalta o de que a política externa seria a alta política, de características muito complexas. A política externa representaria os interesses nacionais (ou os interesses permanentes), constituindo-se, portanto, em uma política de Estado. Por isso, se diz que há uma relativa continuidade. Em relação aos governos, ressalva-se o surgimento de algumas mudanças de estilo ligadas à personalidade e ao estilo individual dos atores, bem como de adequação aos constrangimentos conjunturais. ${ }^{3}$

Ariane Figueira sustenta que o sistema internacional contemporâneo tem, no entanto, como uma de suas características a heterogeneidade das formas de governo dos Estados que o integram. Os Estados democráticos necessariamente atuam num contexto no qual nem todos são democráticos ou procedem de boa-fé. Daí - apesar da crescente publicidade da conduta externa dos Estados - a efetiva existência de limites ao ideal de diplomacia aberta. Por isso, mesmo as democracias, quando atuam no campo diplomático, exercem o poder de maneira mais opaca. Isso se explica como a política externa enseja o sigilo. (FIGUEIRA, 2011).

A prioridade dada ao Poder Executivo na condução das relações externas do Brasil, não significa que é exclusiva e que haja ausência de

3 A política externa é constituída por um conjunto de iniciativas que emanam do ator estatal, tendo em vista mobilizar para o serviço o máximo de fatores disponíveis tanto no ambiente interno como no ambiente externo. (MERLE, 1992, p.18). 
relevo na execução dessa politica publica. A Constituição Federal (CF) brasileira não a trata como domínio exclusivo do Chefe de Estado. $\mathrm{O}$ Parlamento tem uma participação fundamental na formação da vontade do Estado brasileiro na assunção de obrigações perante a comunidade internacional, que é um dos elementos primordiais do exercício da soberania externa de um Estado. ${ }^{4}$ Para além das regras de repartição de competências, a nossa CF determina normas substantivas a pautarem a conduta do Estado brasileiro nas relações exteriores. 5(BORGES, 2014, p.229-230).

Nas discussões que envolvem a relação da democracia com a política externa duas razões são apresentadas para explicar a incidência da primazia do poder executivo. Uma delas é o elevado grau de imprevisibilidade que marca a realidade de um sistema internacional acentuadamente heterogêneo e que induz o governo de cada Estado a adotar - em relação a outros Estados, mas, por via de consequência, também em relação às demais instâncias estatais e aos próprios governados - decisões que se tomem e implementem com maior rapidez. A outra razão invocada diz respeito à noção das relações exteriores como um campo de conhecimento extremamente especializado, próprio da atuação de peritos, marcado por padrões de continuidade que não permitem as oscilações particulares às mudanças políticas internas a um Estado.

Ora, quando se discute a gestão democrática da política externa do Estado, faz-se referência a uma condução dos assuntos relativos à

4 Nos termos dos artigos 52,IV, 49,I e II e inciso XIV da Constituição Federal fica clara a previsão do controle exercido pelo parlamento brasileiro no âmbito das relações externas.

5 É bastante relevante sobre a discussão da repartição de competências entre executivo, legislativo e judiciário em material de politica internacional ler a Relatório n. 11.243 quando da decisão sobre o caso Battisti no Brasil. Por esse relatório se tem o entendimento da complexidade da relação politica interna e internacional. (STF, Reclamação n. 11.242, 2011). 
política exterior que se dê em conformidade com a orientação pretendida pela maioria dos membros do corpo político. Segundo Lopes (2008, p. 100):

Não há democracia concebível sem a participação, direta ou mediada por instituições, dos cidadãos nos assuntos relevantes à vida da polis. E, considerada a crescente relevância de questões internacionais, é razoável supor que a política externa integre o rol de políticas do Estado importantes para a autodeterminação de seu povo. ${ }^{6}$

A gestão democrática da política externa do Estado faz referência à condução dos assuntos relativos à política exterior que se dê conforme a orientação pretendida pela maioria dos membros do corpo político. Quanto maior e mais bem informada essa maioria, potencialmente mais densa será a experiência democrática vivida (LOPES, 2013).

Aparece, portanto com destaque a relação direito à informação/ estado de direito como condição de possibilidade de plenitude democrática.

Com efeito, para Ferrajoli (2007, p. 419), a informação constitui o objeto de dois direitos distintos: o direito de informação como direito ativo de liberdade (denominado por ele de liberdade de ou faculdade) (FERRAJOLI, 2007, p. 336-337), e como direito social passivo consistente em uma expectativa positiva (direito $a$ receber informações).

Restringindo a análise a este segundo sentido - o direito a receber informações - verifica-se que o mesmo é um direito autônomo e coletivo

6 Com relação ao conceito de democracia empregado nesse estudo é entendida como o tipo de governo realizado pelo povo, mas não, necessariamente, um governo pelas mãos do povo (por ele diretamente executado) ou para o povo (em benefício direto da maioria da população). As consequências aferíveis de uma opção democrática dependem de como as instituições econômicas, sociais e políticas a processam. 
que pertence a todos e a cada um simultaneamente (FERRAJOLI, 2007, p. 419). Por isso requer o mesmo explícitas garantias constitucionais (sendo as garantias primárias as obrigações dos poderes públicos a prestar as informações, e as garantias secundárias a possibilidade de exigi-las em juízo, ou seja a sua justiciabilidade).

Explicitando seu pensamento, Ferrajoli divide a transparência pública em duas dimensões: Em primeiro lugar, ex parte principis, a transparência dos poderes públicos e a informação sobre a sua gestão são uma precondição elementar da democracia, e mesmo antes disso, do direito público (recorda ele a fórmula transcendental do direito público kantiana) (FERRAJOLI, 2007, p. 420).

Em segundo lugar, ex parte populi, a informação relativa aos assuntos públicos é a condição necessária para o exercício do direito de voto consciente (isto é, com total conhecimento) (FERRAJOLI, 2007, p. 420). Em reforço, evoca a passagem de Tocqueville na qual este afirma que a soberania do povo e a liberdade de imprensa são duas coisas correlatas.

Resumindo, entende ele que:

La fondatezza, la correttezza e la completezza dell'informazione pubblica sono dunque essenziali così alla trasparenza, alla legalità, alla rappresentatitività e alla responsabilità dei pubblici poteri, come al controllo popolare e all'esercizio consapevole del diritto di voto (FERRAJOLI, 2007, p. 420).

Por isso, reivindica a constitucionalização das garantias do máximo acesso possível (tanto ativo quanto passivo) à informação e à comunicação políticas (FERRAJOLI, 2007, p. 421). 
Tem-se assim que, a partir de uma perspectiva garantista, o direito fundamental à informação (correlativo à transparência governamental, materializado no princípio/dever de publicidade administrativa) é uma imposição do constitucionalismo democrático que está a exigir a construção do máximo de garantias para possibilitar o pleno acesso dos cidadãos às ações e informações estatais.

A política externa como política pública consiste em termos mais amplos nas múltiplas abordagens em que o setor público, em conjunto com o empresariado, as ONGs, a imprensa e a população nacional, desenvolve uma política participativa, que busca servir o interesse nacional com suporte doméstico e credibilidade fora do país. ${ }^{7}$

A política externa como política pública esteve historicamente longe da sociedade civil. Ao longo do tempo, a atividade diplomática vinculou-se à esfera governamental, oficial, dos especialistas em política externa, os quais se incumbiam de planejar e executar as ações externas do Estado, informando os seus resultados a um público passivo. Esse formato colide com aquele que permite a participação de atores não governamentais, não como meros observadores, e sim como praticantes da política externa nacional, promovendo trocas mais simétricas com o governo, por meio de diálogos frequentes e institucionalizados. (CHITTY, 2009).

A ciência politica traz em suas recentes analises a necessidade de se compreender a política externa como política pública. Os fundamentos apresentados salientam que a politica externa devido as mudanças no caráter de regulamentação institucional, cada vez mais conecta-se

7 O conjunto de relações externas de um país são determinados a partir de procedimentos complexos, que envolvem inúmeros parâmetros fixados por agentes distintos. Dessa forma, determinados organismos públicos, entidades privadas, organizações não governamentais, enfim uma quantidade grande de agentes, a partir de determinados critérios, valores, interesses e objetivos próprios, procura intervir no processo decisório acerca da inserção do país no quadro das relações internacionais. 
ou confunde-se com politicas de caráter distributivo, redistributivo e regulatório é parte da estrutura decisória necessária em Estados democráticos. Quando se observa as concepções normativas a relação do continuum e política pública permite que se institua uma nova abordagem dos processos decisórios que estão mais plurais e complexos e não mais circunscritos a tipologia pré-definida de que a politica interna é distinta da externa. (SANCHEZ; SILVA; CARDOSO; SPECIE, 2006).

Nas democracias representativas modernas, os governantes devem exercer seus mandatos conforme a vontade ou interesses do povo. Legislativo e Executivo não exercem o poder em nome próprio, eles representam o povo. Dessa relação de representação advém sua legitimidade. Por causa dela, as leis aprovadas pelo legislativo e sancionadas pelo executivo são vistas como expressão da vontade popular.

A representação democrática vem sofrendo várias críticas em função da suposta incoerência do processo democrático, o poder desmedido dos grupos de interesse e a preponderância do poder econômico sobre o poder político. A crítica à incoerência do processo democrático segundo alguns cientistas sociais é caótica, pois caótico é para eles (segundo os pressupostos da teoria dos jogos) o processo político. Em consequência, o ideal de governo da maioria é inatingível, não por razões práticas, mas pelo caráter naturalmente paradoxal das votações. (SCHUMPETER, 1950).

Uma outra crítica a representação democrática identifica o papel dos grupos de interesse. Aponta-se que mesmo em uma democracia representativa, as leis e políticas públicas implementadas pelo Estado tendem a favorecer as minorias organizadas. Essas minorias dominam a política e fazem com que sua vontade e seus interesses prevaleçam sobre 
os da maioria dos cidadãos. ${ }^{8}$

A crise do Estado não guarda relação apenas com a dimensão econômico- financeira ou com questões ligadas à autonomia burocrática. Refere-se ao esgotamento das formas de articulação Estado-sociedade, sobretudo na modalidade de relacionamento entre os setores público e privado prevalecentes nos modelos de desenvolvimento anteriormente trabalhados.

Se antes o Estado era visto como elemento de contenção da sociedade civil, agora, a sociedade civil e o Estado deveriam atuar conjuntamente a fim de estreitar a distância entre o político e o social. A crise do Estado pôs em primeiro plano a necessidade de eficiência e de qualidade na prestação de serviços públicos, pari passu com a difusão dos ideais democráticos. Isso seria o efeito direto da globalização, ou seja, reclama-se internacionalmente uma melhor gestão dos recursos públicos e por outro uma maior sensibilidade às demandas do demos. A contraindicação desses remédios da globalização é que a suposta busca por eficiência tem servido de justificativa para o aumento da autonomia da administração pública, reforçando-se a centralização reguladora do Estado e o divórcio entre o executivo e o sistema de representação, a despeito da abertura política. Se identifica eficiência em um contexto democrático quando há um bom relacionamento entre burocratas e políticos. ${ }^{9}$

A lógica da ação coletiva distorce completamente o suposto

8 Com base nesses pressupostos a teorias econômicas sustentam que os grupos de interesse possuem influência desproporcional na política. Isso se deve a lógica perversa da ação coletiva, a qual indica que, quanto maior o número de pessoas beneficiadas para uma política pública, menores são os incentivos para que cada indivíduo se esforce para implementa-la.

9 Existe eficiência quando as políticas definidas pelos mandatários da nação (democraticamente eleitos e/ ou devidamente representados no processo decisório) são implementadas pelas burocracias, com a gestão competente dos fundos que lhes forem destinados. A eficiência na prestação desses serviços pressupõe a existência de mecanismos de controle democrático sobre as ações de tais burocratas. 
mercado das leis e políticas públicas. Ela incentiva os grupos de interesse a se organizarem para defender suas causas particulares junto ao Estado, ao tempo em que faz com que a maioria da população permaneça inerte, desinteressada pelos assuntos públicos. Para obter leis e políticas públicas que os beneficiem, os grupos de interesse mobilizam os interessados, financiam campanhas, custeiam estudos sofisticados, fornecem informações à mídia, pressionam e subornam parlamentares. Tudo isso enquanto a maioria continua apática, desinformada e incapaz de se organizar. (PINTO, 2009).

As críticas quanto à representação democrática encontram eco na realidade. Se observarmos com atenção verificaremos que os métodos e votação são imperfeitos, os grupos de interesse têm poder desproporcional ao seu tamanho e o poder econômico exerce grande influência sobre o poder político, refletindo a lição de Bobbio sobre a promessa não cumprida da democracia, relativamente à influência dos interesses privados na esfera pública (BOBBIO, 1986, p. 24) Isso simplesmente nos faz refletir que o ideal democrático não foi totalmente alcançado, não que a democracia seja uma ilusão. ${ }^{10}$

Conforme aponta Pinto (2009, p. 53):

No fundo, o interesse próprio dos políticos, que querem se reeleger ou alcançar postos mais altos no governo, faz com que as políticas públicas se aproximem dos interesses ou da vontade do povo como um todo. Embora as capacidades dos grupos de interesse e controlar e manipular informações seja grande é implausível supor que o povo seja

10 Nos Estados Unidos um estudo revelou que embora a influência dos grupos de interesse na política seja realmente desproporcional ao seu tamanho, os governantes frequentemente aprovam as leis e políticas públicas consistentes com o interesse geral. De acordo com esse estudo, os grupos de interesse funcionam muito mais como um contrapeso ao poder da maioria do que como uma forca determinante no processo político. 
enganado por eles indefinidamente. Pelo menos nas questões interessam ao povo, é natural que as ações dos representantes sejam pautadas pela vontade popular ou pelo interesse coletivo.

De acordo com Christopher Hill a política externa deve ser conduzida em favor do povo em um sentido fundamental. Mas o que se verifica é que, embora em grande parte produzida em nome do povo alegando seus operadores ter as suas mãos atadas pela opinião pública - pouca evidência desse constrangimento existe na prática. Segundo o autor, os diplomatas têm formado uma classe transnacional marcada por relações pessoais, casamentos internos, conferencias subsidiadas e multilinguismo - o que tende a distanciá-los de seus próprios corpos políticos. (HILL, 2003).

Sobre o ponto de vista da teoria democrática o delineamento das fronteiras entre o Estado e a sociedade civil cria um contexto na esfera pública ou espaço cívico no qual o Estado e os atores não estatais buscam influenciar a forma e o conteúdo da política. As organizações da sociedade civil e os seus representantes jogam papéis estratégicos na negociação, articulação e no encaminhamento de seus interesses vis-à-vis o Estado e são cruciais na sustentação democrática das regras e procedimentos. (NEL; VAN DER WESTHVIZEN, 2004).

\section{DEMOCRATIZAÇÃO DA SOCIEDADE CIVIL, PARLAMENTOS E POLÍTICA EXTERNA NA AMÉRICA LATINA.}

É importante compreendermos que com os distintos processos de democratização no subcontinente latino-americano a sociedade civil tornou-se um efetivo ator das políticas governamentais. Em consequência, 
não podemos entender as dinâmicas políticas de cada país da região abstraindo-as de um olhar sobre as sociedades civis respectivas.

Assim, para poder generalizar sobre a sociedade civil no contexto latino-americano, devemos entender as características que ela possui em cada nação. As teorias sobre a sociedade civil que derivam dos âmbitos da filosofia social produzem visões idealizadas que possuem pouca relação com os fenômenos sociais concretos. O mercado não é um mundo orientado exclusivamente pelo interesse (já que também sofre influência dos fatores afetivos, valores e relações de confiança), e nem o Estado é uma burocracia sem coração cujo único objetivo é a dominação. E nem mesmo a sociedade civil constitui um espaço exclusivamente dirigido por valores solidários e de participação, pois nela os interesses e as relações de dominação e a burocratização também desempenham um papel importante. (SORJ, 2010)

No Chile, por exemplo, a relação com o Estado teve uma importância histórica para a sociedade civil chilena, relação que foi direcionada principalmente através da política. Na transição para a democracia, verificou-se nesse âmbito uma perda da centralidade da política e dos partidos. No campo político é preciso incluir a tradição presidencialista do Estado Chileno, reforçada pela Constituição de 1980 e não modificada nesse aspecto pelos governos da concertação pósditadura. Isso diminuiu sensivelmente as atribuições do Parlamento, transformando o executivo de fato no co-legislador através de diferentes vias: matérias que são de sua iniciativa exclusiva, poder de veto, e administração da agenda legislativa via tramitações de urgência. Os vínculos com a sociedade civil são produzidos a partir de instâncias muito menos formais e institucionalizadas do que aquelas próprias das 
instituições democráticas, como o parlamento. ${ }^{11}$ (DELAMAZA, 2010).

No caso do Chile a condução da política exterior é responsabilidade do poder executivo com o concurso de outros atores institucionais e sociais: também deve intervir nela o poder legislativo com suas capacidades e instrumentos próprios, a partir do entendimento de que a maior participação do legislativo deveria conduzir a uma melhor representação dos interesses da sociedade chilena na agenda de política exterior.

Na América Latina há vários trabalhos centrados no estudo dos poderes legislativos e outras instituições do Estado. Há estudos que descrevem e analisam o legislativo e suas funções e suas relações com o executivo. Outros estudos giram em torno dos atores institucionais que intervém na agenda legislativa, suas capacidades, seus recursos e suas interações ou abordam os contextos em que operam os poderes legislativos a fim de examinar semelhanças e diferenças. Nos últimos anos tem aparecido publicações centradas nas funções de controle e fiscalização dos atos do governo pelo poder legislativo. ${ }^{12}$

De outro lado, a cultura política marcadamente presidencialista e as particularidades do sistema eleitoral da maioria dos países latino americanos - nos quais o papel da presidência é central - verifica-se um alto prestígio do executivo ante a opinião pública, frente a um legislativo mal avaliado, percebido como pouco confiável e incapaz de representar

11 No âmbito jurídico desde 2004 está em tramite a Lei de Associatividade e Participação Cidadã na Gestão Pública, sem que até hoje ela tenha sido aprovada. Esse projeto cria a figura de Organizações de interesse público, institucionaliza o Fundo para o Fortalecimento da Sociedade Civil, e estabelece a obrigatoriedade de contar com as normas de participação nos órgãos da administração pública e formar Conselhos de Organizações da Sociedade Civil - mesmo que de caráter consultivo e sem padrões para sua constituição - em todos os níveis da administração. (FERNANDEZ; ORDONEZ, 2007).

12 Nas práticas de diversos parlamentos no mundo há um conjunto de iniciativas e inovações que apontam o incremento da transparência nas políticas públicas e muito em específico nas políticas de segurança incluídas as relações exteriores. Não obstante os trabalhos existentes e o avanço em direção a um maior conhecimento acerca dos poderes legislativos da América Latina e do Chile em particular há muito a saber sobre o trabalho dos parlamentares e seu grau de profissionalização e os fatores e variáveis que intervém. 
e canalizar adequadamente as inquietudes cidadãs frente ao sistema político central de tomada de decisão. ${ }^{13}$

Colômbia, Brasil e Chile são caracterizados por um sistema presidencialista com regime democrático, previstos em suas Constituições. No entanto, é possível verificar diferenças e similaridades entre seus parlamentos em matéria de composição de parlamentares, competências, atribuições. Os parlamentos bicamerais possuem as funções constitucionais de representar o povo, legislar sobre assuntos de interesse nacional, fiscalizar a utilização de recursos públicos e cobrar prestação de contas, autorizar processos contra o Presidente da República e Ministros de Estado, entre outras funções. A composição desses parlamentos se dá através da eleição popular com o número de parlamentares sendo determinado por habitantes, territórios ou regiões.

Na Colômbia, no Brasil e no Chile compete ao Presidente da República celebrar tratados ou convenções internacionais e compete ao Parlamento aprová-los ou rejeitá-los, como podemos ver no Art. 150, parágrafo 16 e no Art. 224 da Constitución Política de 1991, da Colômbia; no parágrafo I do Art. 49 da Constituição Federal de 1988, no Brasil e nos Arts. $32,17^{\circ}$ e $50,1^{\circ}$ da Constituição do Chile. ${ }^{14}$

$13 \mathrm{O}$ poder judiciário costuma desempenhar um importante papel na contenção do poder das maiorias políticas contra os direitos dos indivíduos, por meio do chamado controle de constitucionalidade. À Suprema Corte de um país é frequentemente designado analisar a constitucionalidade daqueles acordos internacionais a que adere o Estado, depois de assinados pelo executivo e ratificados pelo legislativo. Via de regra, tal poder atuará sobre as questões de política externa de forma reativa e indireta, embora não precise ser provocado para tanto. Questões que lhe competem dizem respeito a casos de concessão de asilo político, extradição, interpretação de tratados, conflito entre legislações. (ARANTES, 2007)

14 No caso da Colômbia, expressa o Art. 150 [..]Corresponde al Congreso hacer las leyes. Por medio de ellas ejerce las siguientes funciones: Aprobar o improbar los tratados que el Gobierno celebre con otros Estados o con entidades de derecho internacional. Por medio de dichos tratados podrá el Estado, sobre bases de equidad, reciprocidad y conveniencia nacional, transferir parcialmente determinadas atribuciones a organismos internacionales, que tengan por objeto promover o consolidar la integración económica con otros Estados. No Brasil o Art. 49 indica [...] é da competência exclusiva do Congresso Nacional I - resolver definitivamente sobre tratados, acordos ou atos internacionais que acarretem encargos ou compromissos gravosos ao patrimônio nacional [..] (BRASIL, 2016); No Chile, a disciplina se distribui nas seguintes normas: Artículo 32. Son atribuciones especiales del Presidente de la República: (...) $17^{\circ}$ Conducir las relaciones políticas con las potencias extranjeras y organismos internacionales, y llevar a 
Nos casos apontados é possível constatar que existe competência específica prevista nas Constituições Nacionais para exercer controle nas ações de relações exteriores. O Congresso Colombiano possui competência prevista na Constituição Política de 1992 para realizar controle político, principalmente através dos seguintes mecanismos: intimação de autoridades (citación), realização de audiências públicas (audiência pública) e proposição de "moción de censura".

Cada Câmara e suas respectivas Comissões Permanentes podem intimar e requerer a presença de autoridades em audiências ou reuniões para a cessão de informações. A ausência ou falta de justificativa da autoridade em questão pode acarretar em uma proposição de Moção de Censura. ${ }^{15}$

Isso demonstra que o Poder Legislativo nos três países analisados possui a prerrogativa de controle político, o que demonstra uma atuação do Parlamento como fiscalizador das atividades do Executivo, numa configuração de equilíbrio entre os Poderes. No entanto, no caso Colombiano apesar de a Moção de Censura ser um mecanismo de controle político e prestação de contas, ela não se mostra como um mecanismo eficaz como é proposta.

No período de 1991 a 2014 foram apresentadas 23 proposições de moções de censura, e nenhuma logrou êxito. Apesar disso, pode-se dizer que ela tem sucesso no sentido de suscitar debates e permitir que a

cabo las negociaciones; concluir, firmar y ratificar los tratados que estime convenientes para los intereses del país, los que deberán ser sometidos a la aprobación del Congreso conforme a lo prescrito en el artículo $50, \mathrm{~N}^{\circ}{ }^{\circ} 1 .^{\circ}$ Las discusiones y deliberaciones sobre estos objetos serán secretos si el Presidente de la República así lo exigiere; [...]Artículo 50. Son atribuciones exclusivas del Congreso: $1^{\circ}$ Aprobar o desechar los tratados internacionales que le presentare el Presidente de la República antes de su ratificación. La aprobación de un tratado se someterá a los trámites de una ley. (CHILE, 2016).

15 São faculdades de cada Câmara: Citar e requerer aos Ministros, Superintendentes, e Diretores e Departamentos Administrativos para que concorram as sessões. As citações deverão ocorrer com uma antecipação de cinco dias e se formulará um questionário escrito. Em caso que os Ministros, Superintendentes ou Diretores de Departamentos Administrativos não acorram, sem desculpas aceitas pela Câmara, esta poderá propor moção de censura. 
imprensa e a opinião pública conheçam em maior profundidade alguns problemas de políticas públicas e ações de governo.

O Congresso Brasileiro possui competência prevista no Art. 50 da Constituição Federal de 1988 para realizar controle político. A Câmara dos Deputados e o Senado Federal, ou quaisquer de suas Comissões, podem convocar Ministros de Estado ou quaisquer titulares de órgãos diretamente subordinados à Presidência da República para prestarem, pessoalmente, informações sobre assunto determinado, importando crime de responsabilidade a ausência sem justificação. ${ }^{16}$

No Brasil além da prestação de informações realizada de maneira pessoal, em audiência, é possível encaminhar pedido escrito de informações. As informações requeridas tanto podem ser um meio de exercer controle sobre o Executivo como sobre as políticas levadas a cabo pelo Executivo. Por exemplo, a Comissão de Relações Exteriores e Defesa Nacional - CREDN, da Câmara dos Deputados, utiliza-se do mecanismo de requerimento de informações para, entre outras coisas, solicitar ao Ministro de Relações Exteriores que forneça parecer contextualizando determinado evento que está ocorrendo no cenário internacional, ou que preste informações sobre como o governo se posiciona em relação a algum evento no cenário internacional.

Já no Chile, dispõe a Carta Magna respectiva que a fiscalização de atos do Governo compete à Câmara dos Deputados (art. 48, $1^{\circ}$ ), bem como atribui à mesma entidade o recebimento ou não de denúncia envolvendo altos cargos do Executivo para efeitos de processamento, que correrá junto ao Senado (art. 48, $2^{\circ}$ ).

16 Expressa a Constituição brasileira em seu Art. 50 [...] A Câmara dos Deputados e o Senado Federal, ou qualquer de suas Comissões, poderão convocar Ministro de Estado ou quaisquer titulares de órgãos diretamente subordinados à Presidência da República para prestarem, pessoalmente, informações sobre assunto previamente determinado, importando crime de responsabilidade a ausência sem justificação adequada. [...] (BRASIL, 2016). 


\section{COMPETÊNCIAS E ATRIBUIÇÕES DAS COMISSÕES NOS PARLAMENTOS}

As comissões dos parlamentos brasileiro, colombiano e chileno são órgãos permanentes, de caráter técnico-legislativo ou especializado que têm por finalidade apreciar os assuntos ou proposições submetidos ao seu exame e sobre elas deliberar. Sendo assim, as comissões especializadas representam um espaço de maior participação dos parlamentares no processo decisório do legislativo frente ao poder executivo, através das comissões especializadas, o Parlamento pode ter um papel mais ativo de controle político e de influência no processo legislativo.

Quadro 1 - Formas de Controle de Política Externa exercidas pelos Parlamentos da

Colômbia, Brasil e do Chile

\begin{tabular}{|l|l|l|l|l|}
\hline Pais & Comissão & $\begin{array}{l}\text { Número de } \\
\text { parlamentares }\end{array}$ & Função & Campo temático \\
\hline
\end{tabular}




\begin{tabular}{|c|c|c|c|c|}
\hline $\begin{array}{l}\text { Co- } \\
\text { lômbia }\end{array}$ & $\begin{array}{l}\text { Comissão } \\
\text { Permanente } \\
\text { de Relações } \\
\text { Externas }\end{array}$ & $\begin{array}{l}19 \text { parlamen- } \\
\text { tares }\end{array}$ & $\begin{array}{l}\text { Requer infor- } \\
\text { mações orais } \\
\text { ou escritas } \\
\text { de pessoas } \\
\text { naturais ou } \\
\text { jurídicas }\end{array}$ & $\begin{array}{l}\text { Politica Internacional; } \\
\text { defesa nacional e força } \\
\text { pública, tratados públi- } \\
\text { cos, comércio exterior } \\
\text { e integração econômi- } \\
\text { ca, relações parlamen- } \\
\text { tares, internacionais } \\
\text { e supranacionais, } \\
\text { assuntos diplomáticos } \\
\text { que não sejam constitu- } \\
\text { cionalmente exclusivos } \\
\text { do governo, fronteiras, } \\
\text { entre outros temas. }\end{array}$ \\
\hline Brasil & $\begin{array}{l}\text { Comissão } \\
\text { de Relações } \\
\text { Exteriores } \\
\text { e Defesa } \\
\text { Nacional - } \\
\text { CREDN }\end{array}$ & $\begin{array}{l}33 \text { parlamenta- } \\
\text { res titulares e } 31 \\
\text { suplentes }\end{array}$ & $\begin{array}{l}\text { Apreciação } \\
\text { de matérias, } \\
\text { as Comissões } \\
\text { promovem, } \\
\text { também, } \\
\text { debates e dis- } \\
\text { cussões com } \\
\text { a participação } \\
\text { da sociedade } \\
\text { em geral, so- } \\
\text { bre todos os } \\
\text { temas ou as- } \\
\text { suntos de seu } \\
\text { interesse. }\end{array}$ & $\begin{array}{l}\text { Relações diplomáticas } \\
\text { e consulares, econô- } \\
\text { micas e comerciais, } \\
\text { culturais e científicas, } \\
\text { bilaterais, regionais e } \\
\text { multilaterais; política } \\
\text { externa brasileira; polí- } \\
\text { tica de defesa nacional; } \\
\text { tratados internacionais; } \\
\text { fronteiras, e outros } \\
\text { assuntos pertinentes. }\end{array}$ \\
\hline
\end{tabular}




\begin{tabular}{|c|c|c|c|c|}
\hline Chile & $\begin{array}{l}\text { Comissão } \\
\text { de Relações } \\
\text { Exteriores e } \\
\text { Defesa }\end{array}$ & $\begin{array}{l}18 \text { Parlamen- } \\
\text { tares }\end{array}$ & $\begin{array}{l}\text { Formular e } \\
\text { apreciar pro- } \\
\text { jetos de leis } \\
\text { referentes a } \\
\text { política exter- } \\
\text { na e coordenar } \\
\text { as atividades } \\
\text { interparlamen- } \\
\text { tares. }\end{array}$ & $\begin{array}{l}\text { Relações diplomáticas, } \\
\text { políticas de defesa, } \\
\text { fronteiras, relações } \\
\text { comerciais, integração } \\
\text { regional, entre outros } \\
\text { temas. }\end{array}$ \\
\hline
\end{tabular}

Fonte: Autoria própria, 2016.

A Segunda Comissão Constitucional Permanente da Colômbia da Câmara de Representantes é uma das sete comissões permanentes especializadas do Congresso Colombiano e é composta de 19 parlamentares. Segundo o Art. 137, Constituição Colombiana de 1992, as Comissões podem requerer informações orais ou escritas de pessoas naturais ou jurídicas, e, no caso da ausência de resposta, a Corte Constitucional Colombiana, órgão judicial, fica encarregada de decidir sobre o assunto.

O campo temático de atuação desta Comissão inclui política internacional, defesa nacional e força pública, tratados públicos, comércio exterior e integração econômica, relações parlamentares, internacionais e supranacionais, assuntos diplomáticos que não sejam constitucionalmente exclusivos do governo, fronteiras, entre outros temas.

Já a Comissão de Relações Exteriores e Defesa Nacional CREDN é uma das 22 comissões permanentes do parlamento brasileiro e a sua composição partidária é proporcional à da Câmara. São, atualmente, 33 parlamentares titulares e 31 suplentes que integram a Comissão. Além das funções de apreciação de matérias, as Comissões 
promovem, também, debates e discussões com a participação da sociedade em geral, sobre todos os temas ou assuntos de seu interesse. ${ }^{17}$

A Constituição da República do Chile, reformada em 2005, contempla um conjunto de funções e atribuições legislativas do Executivo a faculdade de iniciativa exclusiva em certas matérias. As funções do poder legislativo (Câmara dos Deputados e Senado) são representar o cidadão, concorrer a formação de leis, e, como visto acima, fiscalizar os atos do governo e exercer funções de tribunal político. Em certos termos o Congresso atua plenamente, como por exemplo na aprovação e tratados internacionais, a declaração de estado de exceção constitucional ou a expedição de indultos penais.

O parlamento chileno tem algumas atribuições exclusivas entre elas a fiscalização das atividades do governo e o início de acusações constitucionais. Frente às relações exteriores e a defesa do Congresso Nacional tem um baixo perfil cumprindo um papel de colaboração e assessoria com as instâncias do executivo, principalmente mediante as suas comissões de relações exteriores e defesa.

Nos termos relacionados as relações exteriores do Chile destacam os representantes de grêmios empresariais para sua preparação e se observa relativamente pouca intervenção dos institutos e centros de estudo. Em matéria de política exterior a agenda é liderada pelo executivo sem grande intervenção do Parlamento. As comissões de estudo do Senado e da Câmara se limitam a ratificar ou aprovar a política exterior

17 Segundo o Art. 58 da CF/88, as Comissões do parlamento brasileiro podem discutir e votar projetos de lei, realizar audiências públicas com entidades da sociedade civil, convocar Ministros de Estado para prestar informações, solicitar depoimento de qualquer autoridade ou cidadão, entre outras competências. As atribuições específicas da Comissão de Relações Exteriores e Defesa Nacional - CREDN estão reguladas pelo Art. 32 do Regimento Interno da Câmara dos Deputados, que prevê que compete à CREDN a apreciação de matérias referentes aos seguintes campos temáticos: relações diplomáticas e consulares, econômicas e comerciais, culturais e científicas, bilaterais, regionais e multilaterais; política externa brasileira; política de defesa nacional; tratados internacionais; fronteiras, e outros assuntos pertinentes. (BRASIL, 2016). 
apresentada pela Chancelaria ou as políticas de defesa. ${ }^{18}$

Os parlamentares poderiam se envolver mais na gênese e no desenvolvimento das iniciativas, nos momentos mais relevantes do processo e tomada de decisão, nas etapas de implementação e de avaliação. O Congresso está em condições de cumprir um rol crucial de controle das políticas com uma orientação inclusiva e pode facilitar a agregação dos interesses sociais em torno deles. (VALDIVIESO, 2007).

Há espaço para se ampliar o debate sobre a prática e a teoria da democratização da política externa no âmbito dos países latinos americanos. A democratização da política externa significa permitir a pluralidade das vozes da sociedade civil abrir acesso a comunicação com os responsáveis no governo pela implementação da política.

Quando se afirma que a política externa é conduzida pela elite, não é somente a política externa do Estado que é conduzida pela elite mas também a alta especialização da própria área das relações internacionais em grande parte dos Estados. Gelson Fonseca Jr. já apontava bem essa discussão quando classificou os estudiosos em dois blocos, quais sejam: os elitistas e os democratas. Os elitistas afirmam que pela gravidade das implicações dos temas internacionais e pelo fato de que o Estado deve ter objetivos permanentes a influência da opinião pública deve ser minimizada. A política externa deve prevalecer sobre a nacional. Já para os democratas a defesa da participação popular ampliada de cunho democrático nos negócios internacionais eliminaria um vício central do comportamento dos Estados, que é a tendência a usar instrumentos militares para fazer valer seus interesses. (FONSECA JÚNIOR, 1998).

18 No Chile o legislativo intervém na etapa de discussão dos assuntos e iniciativas legais, fase em que é possível melhorar as análises e influenciar na tomada de decisão. O trabalho do congresso nacional possui diversas limitações e os legisladores devem interagir com o poder executivo avassalador dotado de capacidade de controlar a agenda. Organizações da sociedade civil possuem participação bastante limitada. 
A falta de capacidade institucional do poder legislativo para cumprir o papel fiscalizador servindo assim de freio ao poder executivo, soma-se a relativa inépcia dos Parlamentos em temas de política externa. $\mathrm{Na}$ América Latina a capacidade técnica das legislaturas é baixa, o que implica a inaptidão dos parlamentares para a lida com temas cujo grau de especialidade e complexidade seja maior. (AMORIN NETO, 2006).

De acordo com os informes sobre democracia na América Latina a preservação da democracia e sua expansão não são espontâneas, pois esta forma de governo é um processo que se constitui a partir de um papel importante da vontade popular sobre o que se sustenta o poder do Estado, assim como também as lideranças políticas. É o resultado de uma experiência social e histórica que se constrói cotidianamente através das atividades dos cidadãos. Nesse sentido, constitui um conjunto de princípios, regras e instituições que organizam as relações sociais, os procedimentos para eleger governos e os mecanismos para controlar o seu exercício e o modo em que a sociedade se concebe a si mesma e ao Estado (A DEMOCRATIZAÇÃO, 2004).

No âmbito do contexto latino-americano essa discussão assume um novo contexto diante do Novo Constitucionalismo. Se observarmos a evolução do ocidente em seu contexto histórico-político, prevaleceu uma cultura jurídica unitária que reproduz idealizações normativas a partir de uma racionalização formal e de legalidade estatal, próprias de um modo particular de produção econômico-social. O Estado liberal de base burguesa-capitalista exprimiu em normas jurídicas, as ideias, os objetivos, as necessidades e as relações sociais de segmentos privados e dominantes da sociedade. ${ }^{19}$ (WOLKMER, 2015).

19 O Novo Constitucionalismo Latino Americano surge a partir de lutas e mudanças vinculado a reinvindicação de maior participação popular a partir da necessidade de um novo modelo de organização do Estado e também do Direito. Esse novo modelo deveria se legitimar no ideal de democracia e na identidade 
No sentido contrário a esta tendência histórica, a liberdade e a democracia são essenciais para a cobrança de ações públicas e para chamar atenção dos governantes sobre os problemas e as necessidades existentes. Garantir a liberdade de participação dos cidadãos e fomentar a criação de espaços onde o povo possa interagir com o Governo, a fim de que este compreenda as suas demandas e as atenda é uma necessidade.

$\mathrm{O}$ exercício da cidadania não está mais limitado ao local em que acontecem, processo denominado desterritorializacão. Hoje se pode acessar diferentes culturas, informações, eventos, conhecer pessoas, fazer realizações comerciais com sujeitos de diferentes localidades. Se pode compartilhar tudo isso não somente no ambiente físico dos Estados. As mobilizações sociais não se limitam mais à esfera do local. Mediante essas novas experiências que a sociedade vem compartilhando com diferentes partes do mundo ela passa a poder compreender uma realidade mais complexa.

A democracia como um processo dinâmico que permite a participação política da sociedade civil e que visa à garantia das liberdades dos indivíduos é essencial no âmbito das discussões sobre o acompanhamento da política externa. O povo ainda está muito a margem do processo decisório e do controle dos atos do Estado em matéria de relações externas.

As ideias que surgem a partir do novo constitucionalismo americano como teoria democrática deve relacionar-se coerentemente com a fundamentação democrática inserida nela, alcançando-a por meio de mecanismos de participação popular direta, da garantia dos direitos fundamentais, do procedimento de controle de constitucionalidade promovido pelo cidadão e da criação de regras que limitem os poderes

do cidadão desvinculado de padrões ocidentais a partir das características da cultura latino-americana. 
políticos, sociais e culturais no âmbito das relações exteriores.

\section{CONCLUSÃO}

São percebidas a partir da análise das constituições do Brasil, do Chile e da Colômbia mudanças muito lentas no sentido de maior participação da sociedade civil na produção da política externa no âmbito desses países. A participação da sociedade civil é estritamente pontual, muito em função do que determina a Constituição desses países.

O acompanhamento e participação do cidadão no âmbito das decisões sobre política externa, como política pública que é, deve ser mais amplo. O Novo Constitucionalismo Latino Americano poderia estender sua visão inovadora para uma mudança na engenharia institucional trazendo mais conquista para a sociedade ao latino-americana.

No caso de uma país como o Brasil existe um movimento de contestação do insulamento burocrático do MRE por parcelas da sociedade brasileira, desde movimentos sindicais, grupos empresariais e ONGs, os quais criticam um distanciamento do Itamaraty das demandas setoriais.

Essas demandas ainda estão sendo reconhecidas de forma muito lenta pelos Estados mencionados como um direito inerente à sociedade civil, institucionalizando canais permanentes de diálogos com o cidadão. No entanto, como se percebe, os espaços de participação foram criados pela iniciativa do legislativo e do executivo, o que evidencia um déficit democrático na formulação dos posicionamentos da política externa e a necessidade de que se estabeleça diálogo permanente da sociedade civil com as instâncias decisórias, essenciais para a construção de uma política externa democraticamente orientada em um mundo globalizado. 
Uma maneira possível de institucionalizar o processo de participação na política externa seria a apontada por Maurício Santoro, por meio da criação de um conselho de políticas públicas nacional. Nessa linha é essencial salientar as propostas para a ampliação participativa como e existente no Brasil com a criação de Conselhos Nacionais de Política Externa, que representaria a mais um espaço democrático e participativo, onde pelo menos o cidadão pudesse ser ouvido. (SANTORO, 2007).

Com a consolidação e fortalecimento da democracia no âmbito dos países latino-americanos e do processo de horizontalizacão da política externa, espera-se um futuro com incisiva participacão da sociedade civil na discussão dessa área de atuação estatal, devido à própria evolucão do conceito de sociedade civil a partir do avanço do processo de globalizacão, aliado à crescente importância dos assuntos internacionais na vida do indivíduo.

\section{REFERÊNCIAS}

\section{AMORIN NETO, O. Presidencialismo e governabilidade nas}

Américas. Rio de Janeiro: FGV; Fundação Konrad Adenauer, 2006.

ARANTES, R. Judiciário: entre a justiça e a política. In: AVELAR,L.; CINTRA,A.O. (Orgs). Sistema político brasileiro: uma introdução. São Paulo: Rio e Janeiro: Unesp; Fundacão Konrad Adenauer, 2007.

BOBBIO, N. O futuro da democracia. Rio de Janeiro: Paz e Terra, 1986.

BORGES, Daniel Damásio. Sob o controle jurisdicional da politica externa - notas acerca do caso Battisti no STF. Revista Direito FGV, Rio de Janeiro, v.10, p.221-244, 2014. 
BRASIL. Constituicão da República do Brasil. Brasília, DF

Disponível em: $<$ http://www.planalto.gov.br/ccivil_03/Constituicao/ Constituicao.htm>. Acesso em: 02 abril 2016.

BRASIL. Supremo Tribunal Federal. Reclamação 11.243 República Italiana. Brasília, DF, 8 de junho de 2011. DJe, Brasília, DF, 05 nov. 2011. Disponível em: <

http://redir.stf.jus.br/paginadorpub/paginador. jsp?docTP=TP\&docID=1495257>. Acesso em: 15 out. 2016.

CAMPILONGO, C. Representação política e ordem jurídica: os dilemas da democracia liberal. 1987. 146 f. Dissertação (Mestrado em direito) - Faculdade de Direito, Universidade de São Paulo, São Paulo, 1987.

CHITTY, N. Australian public diplomacy. In: SNOW, N; TAYLOR, P. (Eds) Routlege handbook of public diplomacy. New York:

Routledge, 2009.

DALLARI, P. Constituição e relações exteriores. São Paulo: Saraiva, 1994.

DELAMAZA, G. ONGS: sociedade civil e democracia no Chile pósditadura. In: SORJ, B. Usos, abusos e desafios da sociedade civil na América Latina. São Paulo: Paz e Terra, 2010. p. 49-88

A DEMOCRATIZAÇÃO na América Latina rumo a uma democracia de cidadãs e cidadãos. Santana da Parnaíba: PNUD - Programa das Nações Unidas para o Desenvolvimento, 2004.

DOYLE, M. A liberal view: preserving and expanding the liberal pacific union. In: PAUL, T.; HALL,J. (Eds) Internacional order and the future of world politics. Cambridge: Cambridge University Press, 1999. p. 41-66. 
FERNADEZ, M.; ORDONEZ, M. Participacão ciudadana en la agenda gobernamental de 2007: caracterizacion de los compromissos. Programa Ciudadania y Gestion Publica. Santiago: Universidad de los Lagos, 2008.

FERRAJOLI, L. Principia iuris: teoria del diritto e della democrazia. Bari: Laterza, 2007. v. 2.

FIGUEIRA, A. Introdução a analise de política externa. São Paulo: Saraiva, 2011.

FONSECA JÚNIOR, G. A legitimidade e outras questões internacionais. São Paulo: Paz e Terra, 1998.

HILL, C. The changing politics of foreign policy. New York:

Palgrave, 2003.

JACOBS, L.; PAGE,B. Who influences US foreign policy?. American Political Science Review, Denton, v. 99, n.1, p.107-23, 2005.

LOPES, Dawilson. Política externa e democracia no Brasil: ensaio de interpretação histórica. São Paulo: Editora Unesp, 2013.

A plausibilidade de uma gestão democrática da política externa: algumas hipóteses (insatisfatórias) sobre o caso brasileiro.

Cena Internacional, Brasília, v. 10, n. 2, p. 98-118, 2008.

MERLE, M. La politique étrangère. Paris: PUF, 1992.

MILNER, H. Interests, Institucions and Information. Princenton: Princeton Universiy Press, 1997.

NEL, P; VAN DER WESTHUIZEN, J. Democratizing foreign 
policy? Lessons from South Africa. Maryland: Lexington Books, 2004.

PINTO, M. B. Constituição e democracia. Rio de Janeiro: Renovar, 2009.

SANCHEZ, Michelle Ratton; SILVA, Elaini C. G. da; CARDOSO, Evorah L.; SPECIE, Priscila. Política externa como política pública: uma analise a regulamentação constitucional brasileira (1967-1898). Revista da Sociologia e Política, Curitiba, n. 27, p. 125-143, 2006.

SANTORO, Mauricio. Direitos humanos e participação cidadã no Mercosul: a experiência do Comitê Brasileiro de Direitos Humanos e Política Externa. In: INTERNATIONAL CONGRESS LATIN AMERICAN ASSOCIATION, 17, 2007, Pittsburg. Anais...Pitsburg: [s.n.], 2007. Disponível em: <http:/www.becanestorkirchner.org/ papers/Paper_InglesMauricio_Santoro_Rocha.pdf $>$. Acesso em: 27 mar. 2016.

SCHUMPETER. Capitalism, socialism, democracy. New York: Harper, 1950.

SORJ. B. (Des) Construindo a sociedade civil na America Latina. In: SORJ, B. Usos, abusos e desafios da sociedade civil na América Latina. São Paulo: Paz e Terra, 2010. p. 7-16.

VALDIVIESO, P. Congresso Nacional y Politica Exterior Chilena: estado actual y algunas propuestas. Estudios Internacionales, Chile, n. $158,2007$.

WIGHT, M. A política de poder. Brasília: Ed. Universidade de Brasília, 2002.

WOLKMER, A. Pluralismo jurídico: fundamentos de uma nova 
cultura no direito. São Paulo: Saraiva, 2015.

Como citar: CADEMARTORI, Sérgio Urqukart de. MIRANDA, José Alberto Antunes de. Globalização, constituição e política externa: analise comparada da participação cidadã no Brasil, Chile e Colombia. Revista do Direito Público, Londrina, v. 11, n. 3, p.311-345, dez. 2016. DOI: 10.5433/1980-511X.2016v11n3p311. ISSN: 1980-511X.

Submetido em 31/08/2016

Aprovado em 27/10/2016 